\title{
FRAGMENTO DE UM DISCURSO (DES)PASSIONALIZADO
}

\section{FRAGMENT OF A (UN)PASSIONALIZED DISCOURSE}

\author{
Ilca Suzana Lopes Vilela \\ USP - Universidade de São Paulo ${ }^{1}$ \\ UFRPE - Universidade Federal Rural de Pernambuco ${ }^{2}$
}

\begin{abstract}
RESUMO: Seguindo a trilha do inteligível ao sensível, este artigo pretende mostrar que a enunciação passional reorganiza o dizer comprometido apenas com o factual e seu efeito de objetividade no texto. A partir da dimensão sensível que a assunção das paixões inscreve em seu percurso enunciativo, é possível desvelar os efeitos de sentido que essa estratégia de composição textual aporta às relações entre enunciador e enunciatário, bem como aos efeitos de persuasão. Para isso, escolhemos como objeto as bonecas pretas produzidas artesanalmente em Conceição das Crioulas, comunidade quilombola do sertão pernambucano, mais precisamente um fragmento de texto verbal que constitui o folder explicativo que as acompanha, cuja leitura seguirá pressupostos do quadro teórico da semiótica greimasiana.
\end{abstract}

PALAVRAS-CHAVE: Inteligível; sensível; argumentação; bonecas pretas; semiótica.

ABSTRACT: Following the trail from the intelligible to the sensible, this article intends to demonstrate that the passional enunciation reorganizes the speech committed only with the factual and the objectivity effect produced in the text. From the sensible dimension that the assumption of the passions inscribes on the enunciative path, it is possible to unveil the meaning effects that this strategy of composition contributes to the relation between enunciator and enunciatee, and to the effects of persuasion as well. Thereupon, we choose as an object the black dolls handcrafted in Conceição das Crioulas, a quilombola community located in the wilderness of Pernambuco; more precisely a fragment of a verbal text in the explanatory folder that comes with them, whose reading will follow the assumptions of Greimasian semiotics' theoretical framework.

KEYWORDS: Intelligible; sensible; argumentation; black dolls; semiotics.

\footnotetext{
${ }^{1}$ Mestranda do Curso de Pós-Graduação em Semiótica e Linguística Geral. Bolsista CNPQ.

${ }^{2}$ Técnica em Assuntos Educacionais da Unidade Acadêmica de Garanhuns, expansão da UFRPE.
} 


\section{Introdução}

A proposta deste trabalho insere-se no quadro teórico clássico da semiótica greimasiana e visa a discutir o embricamento entre razão e paixão, gerando uma outra ordem do persuadir em um discurso de divulgação de um produto posto à venda. Nessa direção, acompanham-se os movimentos de distanciamento e aproximação do enunciador em relação ao enunciatário a partir de mecanismos da sintaxe discursiva e da modalização passional.

O elemento que desencadeou nossa problemática foi um fragmento do texto verbal que constitui o folder explicativo das bonecas pretas do quilombo Conceição das Crioulas que, a título de ilustração, apresentamos a seguir:

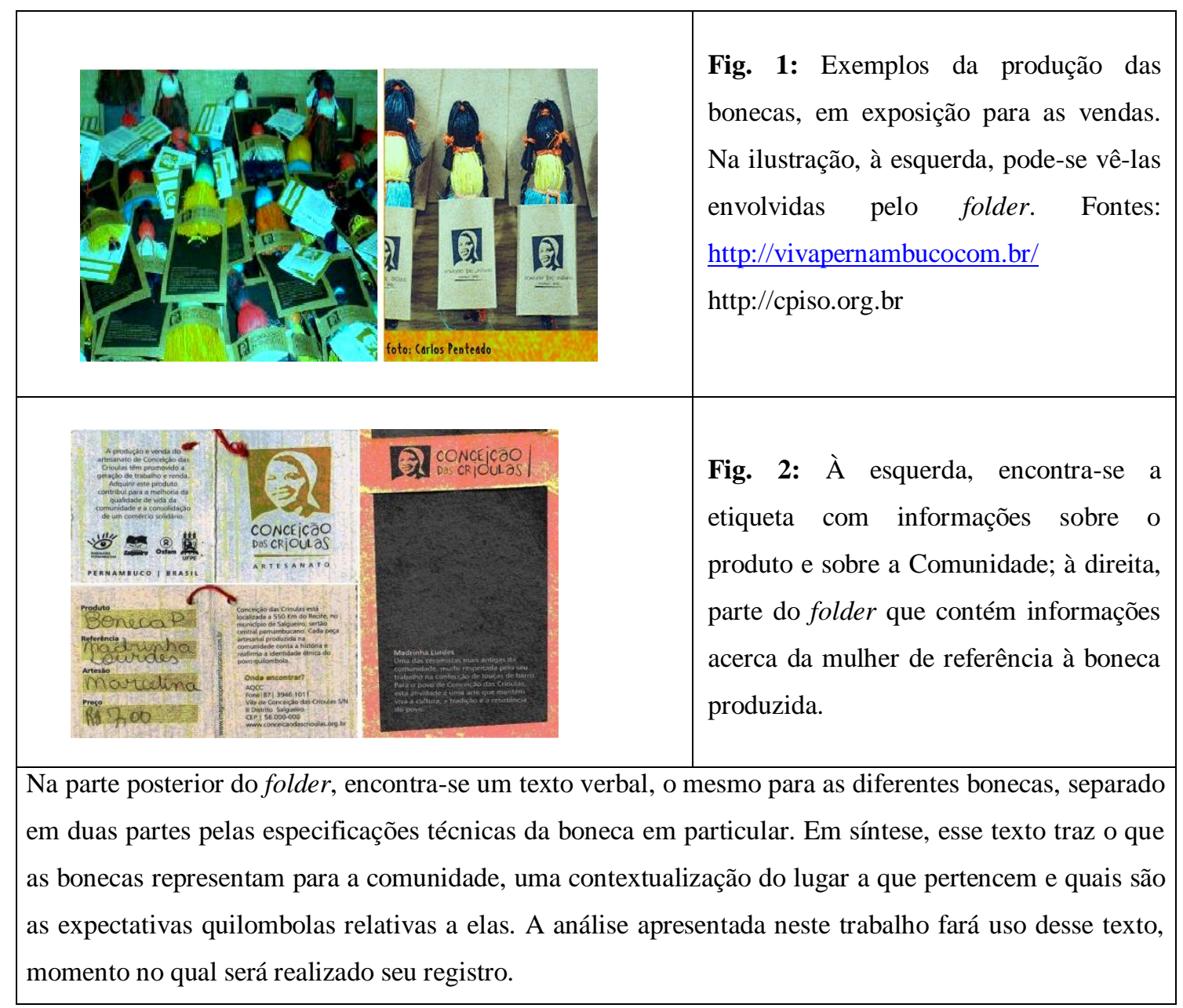

$\mathrm{Na}$ sequência, temos o trabalho de análise organizado em três partes: na primeira, discutiremos o efeito de sentido de objetividade infundido pelo enunciador textual, utilizando-se dos mecanismos da sintaxe discursiva; na segunda, na esteira dos ensinamentos de Greimas e Fontanille (1993), analisaremos a configuração passional do sujeito obstinado, visando a demonstrar como a paixão, no discurso, desconstrói o efeito de objetividade; na terceira, as Considerações Finais, procuraremos debater quais os significados dessa articulação entre objetividade e subjetividade para a argumentação empreendida. 


\section{Da objetividade à subjetividade: a assunção do passional}

\subsection{A sintaxe despassional}

O texto escolhido para a análise tem a função de apresentar a boneca que, metonimicamente, é a parte que comporta o todo (Conceição das Crioulas). Se o primeiro parágrafo concentra-se no objetivo textual, que é o de falar da boneca, esta é símbolo (o povo), modelo (suas mulheres), representação (sua história). Os outros parágrafos, embora concorram para a manutenção da linha isotópica cujo conector é "boneca", afastam-se cada vez mais desse objetivo central ao tratar, no $2^{\circ}$ parágrafo, do contexto (Salgueiro, sertão, Pernambuco, quilombo); no $3^{\circ}$, fala-se dos seus 4000 quilombolas e, no último, reafirma-se o povo de Conceição. Comprovemos pela leitura do texto:

(1)Esta boneca negra é o símbolo da luta e resistência do povo de Conceição das (2)Crioulas. Cada modelo foi desenvolvido a partir de desenhos das mulheres da (3)comunidade, elaborados pelos jovens. Cada uma representa uma personagem (4)marcante da história desse povo que soube a partir da união vencer grandes (5)desafios e que continua forte e atuante na luta das comunidades quilombolas. (6)A $42 \mathrm{~km}$ de Salgueiro - município do sertão pernambucano, encontra-se (7)Conceição das Crioulas, uma comunidade remanescente de quilombo que (8)redescobriu as suas raízes através da atividade artesanal, uma forma de geração (9)de renda e recuperação da auto-estima. (10)Hoje seus cerca de 4000 quilombolas voltam os seus olhos para materiais como (11)o caroá, o barro e o catulé e enxergam a possibilidade de dias melhores. (12)Mas o povo de Conceição quer mais. Quer ter a liberdade para expandir seus (13)domínios, levando com orgulho a sua arte para além da caatinga cercada de (14)xique-xiques.

No entanto, esse movimento, que caminha da boneca para o povo de Conceição, não nega a isotopia da apresentação da boneca, já que cada uma delas é o próprio simulacro de Conceição, ou no dizer enunciado: "Esta boneca negra é o símbolo da luta e resistência do povo de Conceição das Crioulas" (linhas 1-2).

Uma leitura, guiada pelos dispositivos acionados para a constituição de um gênero de um modo geral chamado informativo, disponibiliza elementos que corroboram sua objetividade: relato factual, que envolve relações entre fatos (descrições), pessoas (quilombolas), ideias (sustentabilidade), primando pela informação, pelo dizer verdadeiro, ancorado pelo objetivismo, limpando do texto a presença de um sujeito e de sua subjetividade. Assim, o efeito de dizer objetivo imprime-se, espacialmente, na descrição de um lugar preciso (Salgueiro, sertão de Pernambuco, Conceição das Crioulas); temporalmente, usa-se o sistema enunciativo, como atestam o advérbio hoje e as formas verbais no presente (é, representa, encontra-se, voltam, enxergam). Embora o ato de narrar ocorra, no mais das vezes, posteriormente à história contada, projetando-se, então, o sistema do pretérito no enunciado, há situações em que o narrador, visando criar o efeito de sentido de evento que está em pleno acontecimento, institui uma "narração em que haja concomitância entre o tempo da narração e o dos acontecimentos narrados" (FIORIN, 2009, p.63), como verificamos no texto em questão. Isso reforça a ideia de um fato que realmente acontece. Portanto o sujeito da ação, projetado enuncivamente (ele é aquele que não fala e aquele a quem não se 
fala: o povo de Conceição das Crioulas), junto com a espacialização e a temporalização, compõe aspectos sintáxicos de um discurso que se quer objetivo.

Em As astúcias da enunciação (FIORIN, 1996), são fornecidos os meios para que as instâncias do centro dêitico, as quais, no parágrafo anterior, foram brevemente referidas, recebam um tratamento mais abrangente. Dentre outros aspectos desenvolvidos na argumentação do autor, está o de que a própria "História está marcada pela temporalidade, pela espacialidade e pela actorialidade." (FIORIN, 1966, p. 12), e, sendo assim, cabe tratar dessas categorias de sintaxe discursiva, cuja episteme fundadora está no ego (eu), hic (aqui) e nunc (agora) de Benveniste (2006) de maneira mais satisfatória.

No que concerne à categoria de pessoa, o processo de actorialização, embora responda pelo componente sintáxico do discurso, não prescinde dos aspectos semânticos da discursivização, pois a debreagem e a embreagem, mecanismos da sintaxe, ao instalarem, no enunciado, a pessoa, por si só não fazem desta um ator do discurso; é preciso ainda que ela seja revestida por temas e figuras, elementos semânticos. Todavia, neste estudo, não trataremos desses últimos, posto que os elementos sintáxicos nos pareceram suficientes para explorar a construção do efeito de sentido de objetividade no objeto sob análise.

Conforme Benveniste (1966 apud FIORIN, 1996), a marca da pessoalidade, da manifestação do sujeito da enunciação, que se recupera pelo enunciado, é reservada ao eu e ao tu. O ele, por sua vez, é uma não pessoa, dado que "pode representar qualquer sujeito, expresso ou não, não é jamais instaurado como actante da enunciação" (FIORIN, 1996, p. 60). É justamente o que acontece com o objeto desse estudo, em que a estratégia actorial escolhida foi a do emprego da terceira pessoa, um ele, um não sujeito. Portanto optou-se pela retirada da subjetividade, cujos consortes são o eu e o tu.

Como proposto por Fiorin (1996), pensar a enunciação, a partir do simulacro metodológico que é o percurso gerativo do sentido, é considerar um nível fundamental, cujas categorias de base aproximação versus distanciamento fundam todos os efeitos de sentido enunciativos. No nível de superfície, a categoria de pessoa, quando marcada pela subjetividade, corresponderá, no nível profundo, à aproximação, e a objetividade, por conseguinte, responderá pelo distanciamento. Pode-se creditar à pessoa uma individualidade, e à persona, um papel social desempenhado por um indivíduo para dizer que a debreagem enunciva projeta no enunciado uma persona (FIORIN, 1966). Levando em conta essas considerações, na leitura que se vem fazendo do fragmento textual, pôde-se verificar que não há uma projeção do sujeito da enunciação no enunciado, pois, devido à debreagem enunciva, tem-se um efeito de distanciamento, de objetividade discursiva.

De acordo com Benveniste (2006), em semiótica, a abordagem da categoria temporal considera, inicialmente, que não se trata da exploração do aspecto cronológico ou em sua dimensão física, o que se tem em conta é a especificidade de um tempo linguístico, produzido na e pela enunciação. Instaura-se, então, um agora, com base no qual, serão realizadas as oposições temporais em língua, das quais derivam os diferentes tempos linguísticos.

Há, na língua, primordialmente, dois sistemas temporais: o enunciativo, correspondente ao momento da enunciação, e o enuncivo, cuja organização é feita com base nos momentos de referência enunciados. Conforme já apontado, os tempos verbais predominantes no texto em estudo são os do presente, em que coincidem o momento do acontecimento e o de referência, e que se inserem, portanto, no sistema temporal enunciativo. Existem, em razão de suas particularidades, diferentes classificações para o presente. Apesar de não nos determos nelas, cumpre ressaltar que a análise apontou o uso do presente 
omnitemporal ou gnômico como o tempo preferido na construção do texto verbal de apresentação das bonecas.

O presente omnitemporal ou gnômico caracteriza-se pela marca de um momento de referência que traz implícito um sempre, visando enunciar verdades que se querem imutáveis. Sua presença é notável nos gêneros científicos, no domínio religioso e em demais textos cuja coerência se garante pela construção do simulacro da imutabilidade. Demonstremos isso a partir de um trecho extraído do nosso objeto: "A $42 \mathrm{~km}$ de Salgueiro município do sertão pernambucano -, encontra-se Conceição das Crioulas, uma comunidade remanescente de quilombo" ( $2^{\circ}$ parágrafo, linhas 6-7). No período escolhido, o verbo negritado faz referência à localização geográfica da comunidade onde são confeccionadas as bonecas, seu sentido é o do sempre, o de permanência: nesse local é possível encontrar (sempre) as bonecas.

Outros mecanismos linguísticos que podem ser considerados no estudo da temporalização são os advérbios, as preposições e as conjunções, sendo que estas últimas não devem ser estudadas categoricamente distinguidas no sistema enunciativo e enuncivo como os primeiros, visto que não incide sobre elas apenas a marca temporal, mas também trazem como componente a aspectualização.

Os advérbios aplicam a cada um dos momentos de referência, o enunciativo e o enuncivo, a categoria topológica concomitância versus não concomitância (anterioridade versus posterioridade). No sistema enunciativo, pode-se expressar concomitância: agora, hoje, atualmente etc.; anterioridade: ontem, anteontem etc.; e posterioridade: amanhã, depois etc. No sistema enuncivo, que faz relação com um momento de referência futuro ou passado inscrito no enunciado, já que não coincide com o momento da enunciação, tem-se, em concomitância: então, aquele etc.; em anterioridade: na véspera, na antevéspera etc.; em posterioridade: mais tarde, no dia posterior etc.

As preposições enunciam a concomitância por meio de: durante, no curso de etc.; já a anterioridade pode ser expressa por: antes de, anteriormente; e após, depois de, por fim, em seguida a etc. manifestam a posterioridade. $\mathrm{O}$ aspecto, como já foi dito, é outra categoria com a qual todas as preposições temporais são organizadas. Assim, uma aspectualização pontual versus durativo (incoativo versus terminativo) constrói relações de sentido que revelam, principalmente, um processo iniciado (incoativo), sua duração no tempo (durativo) e o fim do processo (terminativo).

As conjunções trazem a simultaneidade mediante os termos: quando, cada vez que, todas às vezes etc.; a anterioridade em antes que; e a posterioridade em: depois que, apenas etc. Quanto ao aspecto, tem-se o incoativo em desde que; e o terminativo em até que, com a possibilidade da combinação dos dois em desde que.

Vejamos na tabela abaixo a organização desses elementos linguísticos no texto em estudo:

\begin{tabular}{|l|l|l|l|}
\hline \multicolumn{1}{|c|}{ Categoria } & Elemento extraído do texto & \multicolumn{1}{c|}{ Sistema } & \multicolumn{1}{c|}{ Valor } \\
\hline advérbio & hoje (linha 10) & enunciativo & simultaneidade \\
\hline preposição & através de (linha 8) & aspectual & duratividade \\
\hline conjunção & - & - & - \\
& & & \\
\hline
\end{tabular}


O estudo da temporalização reforça o efeito de sentido de objetividade no texto, seja pela escolha do presente gnômico, que estabelece o dizer verdadeiro ou comprometido em simulá-lo, seja pelos valores de concomitância e progresso durativo instalados, respectivamente, pelo hoje e pelo através de. Este último, suspendendo o início e o fim do processo, expandindo-o em uma duratividade progressiva, apresenta uma produção artesanal quilombola contínua, permanente, corroborando o efeito omnitemporal, conjugandose com este. O hoje introduz o povo de Conceição em sua totalidade, cerca de quatro mil indivíduos situados no presente, a temporalização, enfim, de um fato.

É importante destacar que a última das categorias, a do espaço, dentre as três, é a que tem sido menos explorada. Mesmo Benveniste, em seus estudos, dedicou poucos escritos a ela, sendo que os estudiosos que se ativeram ao assunto, notavelmente teóricos da literatura, consideraram-na em sua semântica (FIORIN, 1996).

A sintaxe do espaço linguístico apresenta-se por meio de pronomes demonstrativos e advérbios de lugar. Trata-se de mecanismos que entram na composição da cena enunciativa, não sendo, portanto, elementos geométricos como os do espaço físico. Demonstremos, operando sobre o texto-objeto em estudo, a partir do quadro que se segue:

\begin{tabular}{|c|c|c|}
\hline Mecanismo & Elemento extraído do texto & Função \\
\hline Pronome demonstrativo & $\begin{array}{l}\text { Esta } \\
\text { (d)esse }\end{array}$ & $\begin{array}{l}\text { designar ou mostrar (dêitica) } \\
\text { coesiva (catafórica, marca o } \\
\text { que já foi dito) }\end{array}$ \\
\hline Advérbio & Além & $\begin{array}{l}\text { dar uma visão de transposição } \\
\text { do espaço }\end{array}$ \\
\hline
\end{tabular}

Outro aspecto a mencionar é o da debreagem espacial, que pode ser enunciativa, se o centro de referência for o espaço do eu que enuncia, ou enunciva, se houver um algures/alhures instalado no enunciado. Esta última marca a tipologia espacial típica do texto sob análise, conforme se pode observar a partir deste excerto: "A $42 \mathrm{~km}$ de Salgueiro município do sertão pernambucano-, encontra-se Conceição das Crioulas". O algum lugar é Conceição das Crioulas, uma espécie de lá distante de um eu e próximo da terceira pessoa que forma a tessitura textual.

Dessa forma, depois de trabalharmos com as categorias que formam a sintaxe discursiva, a pessoa, o tempo e o espaço, visando ao argumento em favor de uma leitura orientada pelo dizer objetivo, procuraremos, na próxima seção, refletir sobre a modalização das paixões fazendo revelar a subjetividade do sujeito quilombola, por meio do percurso de um ator sob o signo da obstinação.

\subsection{A modalização passional}

A motivação para encaminhar a análise à existência modal do sujeito da paixão partiu dos termos quer mais e quer ter (linha 12 do nosso objeto de estudo), os quais 
trouxeram o tônus da emoção, fugindo do simulacro de racionalidade que o discurso como um todo pretendeu infundir. Esse indício linguageiro faz aflorar um sujeito coletivo senciente: o povo quilombola. Seguindo essa pista, e depois de apresentarmos, bastante sumariamente, alguns dispositivos utilizados no estudo das paixões, dando prosseguimento à retomada do fragmento textual que vimos analisando, faremos a análise da sua configuração passional.

O querer, o dever, o poder e o saber são as modalidades operacionalizadas pela semiótica. No caso do estudo das paixões, interessa a incidência desses valores sobre o ser do sujeito passional. São os movimentos orquestrados pelas modalidades que não só determinaram uma sintaxe como permitiram o próprio estabelecimento de um percurso canônico das paixões.

A constituição, a disposição, a sensibilização, a emoção e a moralização são os constituintes do esquema canônico passional. A constituição responde pelo ser do sujeito, ela tem um caráter preparatório para receber a sensibilização; nesse momento, imprime-se um estilo passional. A disposição é concebida como um estado inicial em que os mecanismos modais agem e são distinguidos pelo uso. A sensibilização é a instalação da timia, do estado de quem sofre e age pela paixão. A emoção é o estado intensificado em que um sujeito patêmico é aspectualizado pela crise passional que confere duratividade à sensibilização. E, como etapa final, a moralização que, responsável pelo comportamento dado à observação, mostra que a paixão " está longe de ser física; ela é uma interpretação cultural das perturbações corporais perceptíveis, uma moralização social sobre um fazer individual" (LARA e MATTE, 2009, p.62).

Se indícios do último parágrafo do texto em estudo motivaram a escrita desta seção, é na sua primeira linha, no termo resistência que encontramos subsídios para determinar um papel patêmico para o sujeito de estado, doravante o sujeito quilombola. Conforme Bertrand (2003), a própria razão de ser da resistência é alimentar a vontade de um obstinado. Sendo assim, inscrita e codificada no tecido do texto, resistência implica a paixão obstinação.

A consulta ao Dicionário Houaiss (2008) fornece a seguinte definição de base para a obstinação: "apego forte e excessivo às próprias idéias, resoluções e empreendimentos; pertinácia, persistência, tenacidade". Essa acepção, que cristaliza um dos usos culturais do lexema em Língua Portuguesa, corrobora a conceituação semiótica de obstinado como "aquele que quer, apesar da impossibilidade evidente" (FONTANILLE, 1995, p.182 apud FIORIN, 2007, p.10). Ora é num querer tão intenso, indócil a empecilhos, que fazem sentido as qualificações parassinonímicas do pertinaz, persistente, tenaz.

O obstinado, modalizado pelo querer e fazer, é "o sujeito que não somente quer fazer, mas quer ser aquele que faz, embora saiba que a conjunção a que ele visa pode não se realizar, ou mesmo pode não ser: ele quer apesar dos obstáculos" (BERTRAND, 2003, p 371).

A disposição em jogo, na constituição das modalizações do ser característico da paixão obstinação, é a de um "sujeito capaz de continuar a fazer", é um "fazer apesar de $X$ ". Instala-se um paradoxo, pois se tem "um querer-fazer que sobrevive a um não poderfazer, que lhe serve até de reforço; um fazer que não cessa" (GREIMAS; FONTANILLE, 1993, p. 63, grifo nosso). Tem-se, portanto, um excesso modal, aspectualizado pela dupla possibilidade de continuação de um processo, (i) continuando sem interrupção; (ii) continuando de maneira intermitente. ${ }^{3}$

\footnotetext{
${ }^{3}$ As informações relativas a um processo em continuação, característico da modulação passional do obstinado, foram-me apresentadas pelo Prof. Ivã Carlos Lopes (meu orientador de mestrado), todavia um eventual manuseio incorreto dessas noções será de minha total responsabilidade.
}

Disponível em: http://seer.fclar.unesp.br/casa 
O trecho que se segue demonstra o funcionamento do que se afirmou no parágrafo antecedente: "Mas o povo de Conceição quer mais. Quer ter a liberdade para expandir seus domínios, levando com orgulho a sua arte para além da caatinga cercada de xique-xiques" (último parágrafo do nosso corpus). Nele o sujeito está dotado das seguintes modalizações: um saber-não-ser (o sujeito está disjunto do objeto liberdade); um poder-nãoser (a realização da conjunção com o objeto não é certa, pois é um sujeito cercado pelas constrições de seu próprio território histórico-social e geográfico), mas, ainda assim, um querer-ser (ele quer mais, quer ter, quer ir além, por isso "insiste de todo jeito em ser conjunto e tudo fará para isso"). ${ }^{4}$ Essas modalizações trazem à sintaxe passional do obstinado uma estrutura aspectual fundada na continuidade, cuja configuração mais geral, como já dito, está num "sujeito capaz de continuar a fazer apesar de".

Essa estrutura pode ser recuperada em todas as partes que compõem o texto: está na prática da produção da boneca, um fazer para vencer grandes desafios impostos, historicamente, ao contingente negro em sua luta pela sobrevivência; no próprio percurso de reconstrução identitária a partir do saber tradicional da atividade de artesanato; no crer na possibilidade de dias melhores, cuja geração se funda nos recursos que da natureza adversa do sertão puderam transformar-se em matéria-prima do ousado projeto de ultrapassar suas próprias fronteiras territoriais.

Esse tratamento da modalização passional pretendeu demonstrar como a assunção da paixão no discurso desconstrói o efeito de objetividade, posto que revela a dimensão patêmica como móvel do fazer humano e, por mais despassionalizado que se queira um texto, nele sempre estarão presentes as paixões, fazendo revelar os estados de alma.

A seção que se segue, última dedicada ao processo analítico, procurará combinar, no interior do mesmo quadro teórico-metodológico, os mecanismos com que se organiza o texto aos "fatores contextuais ou sócio-históricos de fabricação do sentido" (BARROS, 2008, p. 8), ${ }^{5}$ de modo a refletir sobre a(s) forma(s) com que o percurso da razão à paixão desdobra-se num fazer persuasivo.

\section{Das relações entre enunciador e enunciatário: a persuasão}

A partir do momento em que dois humanos entram em relação recíproca, o seu contrato, tácito no mais das vezes, entra em vigor. Ele regula a forma das suas relações (BRECHT apud BARTHES, 2004, p. 391).

Todo ato comunicativo tem como principal substrato a persuasão. Há sempre um enunciador pressuposto, responsável pelos valores colocados em discurso, imbuído do querer levar o enunciatário a crer e a fazer (BARROS, 1988; 2008; FIORIN, 2009).

\footnotetext{
${ }_{5}^{4}$ GREIMAS e FONTANILLE, 1993, p. 63.

5 Na linha de pesquisas desenvolvidas por Diana L. P. de Barros (1988; 2008), a conciliação entre análise interna (descrição e explicação dos mecanismos e regras que engendram o texto) e análise externa do texto (exame dos aportes de sentido que o contexto histórico-social gera em sua relação com o texto enquanto objeto cultural) será melhor desenvolvida na seção imediatamente posterior. Todavia o semioticista apreende o contexto a partir do texto, seja seguindo as pistas da pessoa, do tempo e do espaço, seja pelas estratégias de composição do discurso.
} 
O enunciador é o destinador-manipulador ${ }^{6}$ implícito da comunicação destinada ao enunciatário (também pressuposto), que não recebe o ato comunicativo passivamente, mas produz discurso, pois sua leitura dos valores em jogo na enunciação pode aceitar ou não o contrato estabelecido. Dependendo da interpretação dos valores que circulam, realizada pelo enunciatário, este pode considerá-los apreciáveis e convencer-se do estatuto veridictório que infundem, aceitando o contrato ou, no caso de uma persuasão mal sucedida, refutando o contrato inicial porque os seus valores não foram ao encontro do que ele crê como verdade.

O texto que vimos estudando, considerado como um todo de sentido, é organizado por um enunciador que fez suas escolhas, com base nas peculiaridades próprias ao sistema verbal, visando atingir fins determinados. A finalidade do discurso enunciado, entendido no seu diálogo com a sustentabilidade, embora tenha sido construído para apresentar um produto para a venda antes de objetivar apenas o lucro, infunde o estésico, ${ }^{7}$ pois, por meio das histórias dos antepassados que também produziram os mesmos produtos, faz reconhecer e perpetuar as origens e firmar o povo de Conceição como identidade social, deleitando o comprador com narrativas míticas, mas também identificando-o com uma estratégia de fortalecimento e sustentação da identidade de um povo mediante o feminino.

No que concerne aos mecanismos de construção discursiva, no âmbito da enunciação enunciada, as três categorias da enunciação têm de concordar, o que significa que, se a pessoa é enunciativa, o espaço e o tempo deverão também sê-lo na concretude do enunciado. Porém, nada é tão categórico: existe a possibilidade de haver combinações entre o sistema enuncivo e o enunciativo, combinações que podem gerar "diferentes efeitos de sentido e podem talvez até fundar uma tipologia de discursos" (FIORIN, 1996, p. 303). Ora, é possível lançar como hipótese provisória, a ser verificada em corpus bastante para tal, que, no texto em estudo, a mescla dos sistemas da sintaxe discursiva acena para a construção de uma outra maneira de dizer, quando se quer divulgar produtos gerados no seio de discursos de territórios étnicos específicos.

O enunciado verbal demonstra, portanto, que o artesanato, tanto como objeto quanto como texto, constrói-se concomitantemente como produto identitário e como produto da diferenciação, estabelecendo relações de sentido entre o produtor e o comprador, pois manifesta relações com o grupo social de onde se origina e sincretiza um duplo papel: o de objeto de valor pragmático (criado com materiais abundantes e característicos de uma região, por meio de ensinamentos baseados na transmissão oral e aperfeiçoados na prática da própria produção, ele porta valores subjetivos e é passível de julgamento estético), e o de texto (suporte de discursos diversos, dentre os quais se destacam o da identidade social dos sujeitos produtores, o da tradição e o da memória revisitadas, que perpetuam um patrimônio cultural).

Dialogando com a epígrafe desta seção, o contrato que se almejou estabelecer fundamenta-se numa relação recíproca entre enunciador e enunciatário, baseada na fidúcia à noção de sustentabilidade que, carregada de sentidos eufóricos relacionados à qualidade de vida, à existência, à sobrevivência humana e não humana, distancia-se do caráter explicitamente argumentativo e apelativo do domínio publicitário, cuja lógica propalada é a de consumo, a mercadológica, buscando a adesão por intermédio de uma outra ordenação da construção do sentido.

\footnotetext{
${ }^{6}$ A manipulação, em semiótica, não tem o sentido pejorativo com que correntemente é aplicado, trata-se de um engenho discursivo focado na adesão do destinatário; manipular, portanto, é fazer o outro fazer.

7 Em conformidade aos ensinamentos deixados por Greimas (2002), no livro Da Imperfeição, "a estesia é a condição de sentir as qualidades sensíveis emanadas do que existe e que exala a sua configuração para essa ser capturada, sentida e processada fazendo sentido para o outro" (OLIVEIRA, 2010, p.2).
} 
Nessa outra ordem do persuadir, o simulacro da objetividade quis encarnar a veridicção e a confiabilidade, um mesmo uso, mas com fins distintos, já que sua utilização pode ser lida como uma postura desviante do discurso apelativo da publicidade de lógica do lucro, para se filiar ao nicho dos produtos sociais e ambientais e de política identitária étnica, cuja ótica não é meramente lucrar, e sim construir consciências fidelizadas a um projeto de resgate da cidadania, de reconstrução de memórias e da própria identidade de um contingente. De outra parte, e isenta de cunho paradoxal, a efusão da subjetividade, num desfile de diversas figuras que inscreveram valores corolários de uma visão de mundo do homem do sertão, cujo emblema foi o estilo passional de um obstinado, deixa latente nos liames interdiscursivos, a confirmação euclideana de que "o sertanejo é, antes de tudo, um forte" (CUNHA, 1984, s./ind.). É nessa emanação de um "perfume" (GREIMAS; FONTANILLE, 1993) que atravessa todo o discurso que a dimensão sensível colabora na congregação de parceiros balizadores de dado sistema ideológico.

Marcas e produtos traduzem estilos de vida e uma infinidade de engajamentos dos sujeitos, como a identificação com grupos ou causas. E não é diferente o caso do texto com que lidamos, que, situado em um espaço dotado não apenas de recursos naturais, mas também de recursos humanos inseridos na cultura local, na história da comunidade, na memória do grupo, traz relações intersemióticas, cujos elementos de pertença são traduzidos no produto final, afirmando, inclusive, a existência e a sobrevivência da comunidade produtora - tanto do ponto de vista de sua identidade, como de sua cultura popular. Destarte, aqueles que se identificam com essas formas de vida procurarão engajar-se com suas formas de resistência.

Trata-se, portanto, de um discurso que se coloca como reeducador do homem na condução para um novo paradigma da contemporaneidade, emergente e necessário em um outro modo de ser e estar do homem no mundo. Nesse sentido, as mentalidades devem estar ideologicamente sintonizadas com relação, por exemplo, à origem e à reposição da matériaprima e ao descarte (se houver) do produto pelo consumidor. Além disso, elas devem considerar o alcance do resultado da produção como resposta a demandas específicas do meio social em que se insere.

\section{CONSIDERAÇÕES FINAIS}

É evidente que o termo sustentabilidade hoje transita em todos os setores das sociedades, mesmo - e principalmente - os de cunho mercadológico. Na lógica de mercado, que é a lógica do consumo, transporta-se aos produtos e às marcas o matiz da sustentabilidade. Desse modo, cria-se, discursivamente, a ilusão de que o consumo e a produção de objetos ecologicamente corretos são per si suficientes para, de um lado, evitar a degradação do planeta e, de outro, preservar todos os seres e modos de vida neles existentes.

Todavia é notável que o homem contemporâneo, mais informado, reflexivo e engajado vivencia uma fase de consumo bastante diferente do consumidor cego diante das vitrines, que comprava os produtos sem refletir (BAUDRILLARD, 1991), pois ele busca, nos produtos, valores subjetivos ligados à figuratividade e à temática ambiental ou social que, por sua vez, o manipulam ao lhe portar objetos e valores eufóricos e sancioná-lo com a possibilidade de reconhecimento ou de sua inserção em grupos ecologicamente corretos, eticamente responsáveis, política e socialmente conscientes etc. 
Assim sendo, a produção das bonecas pretas dessa Comunidade constrói formas de engajamento e sociabilidade, porque concretiza o resgate da identidade do território e da cultura e aporta aos sujeitos nela viventes uma melhor qualidade de vida, tendo em vista as relações estabelecidas entre os fatores do desenvolvimento local que, por sua vez, manifestam a esses sujeitos o direito pleno à cidadania.

Entretanto as colocações aqui postas pautam-se na disforia por trás da qual se apreende a lógica do consumo, que emprega os discursos ideológicos das pautas internacionais e os ressignifica para a manutenção da circulação de bens, por meio da compra e venda, que visam ao acúmulo de capital. Não podemos negar, porém, que mesmo essa lógica do consumo, que tem uma finalidade bem definida, contribui para a tomada de consciência dos homens com relação aos sentidos da sustentabilidade dos meios de desenvolvimento.

Longe, porém, desse debate em torno da produtividade ou do esvaziamento de sentido do termo sustentabilidade nas sociedades contemporâneas, este trabalho se propôs a discutir o funcionamento de dispositivos semióticos de leitura da ação e da paixão utilizados com vistas a persuadir um certo destinatário e, para isso, assumiu como corpus um texto cuja heterogeneidade discursiva se revela partidária desse novo paradigma humano que é o da sustentabilidade.

Consideramos, especificamente no que se refere ao texto estudado, que este, criado como uma das estratégias argumentativas para convencer o potencial comprador a adquirir o produto boneca, diferenciou-se do estilo próprio dos discursos apelativos voltados à venda, caso da publicidade, pois se assenta num discurso de política identitária, que ultrapassa o fator econômico, porque são igualmente importantes os valores sociais e ambientais. Com esse fim, nas malhas do inteligível ao sensível, vários dispositivos foram acionados para constituição desse intento, mas alguns foram brevemente abordados, cabendo a futuros trabalhos, de maior fôlego, dar conta de questões aqui apenas ensaiadas.

\section{REFERÊNCIAS}

BAUDRILLARD, J. A sociedade do consumo. Lisboa: Edições 70, 1991.

BARROS, Diana Luz Pessoa de. Teoria do discurso: fundamentos semióticos. São Paulo: Atual, 1988.

Teoria semiótica do texto. $4^{\mathrm{a}}$ edição. São Paulo: Ática, 2008.

BARTHES, Roland. O rumor da língua. $2^{\mathrm{a}}$ edição. São Paulo: Martins Fontes, 2004.

BENVENISTE, Emile. Problemas de linguística geral II. $2^{\mathrm{a}}$ edição. Campinas: Pontes, 2006.

Problèmes de linguistique générale. Paris, Galimard, v. 1, 1966.

BERTRAND, D. Caminhos da semiótica literária. Trad. do Grupo CASA, sob a coordenação de Ivã Carlos Lopes et. al. Bauru, SP: EDUSC, 2003.

CUNHA, Euclides da. Os Sertões. São Paulo: Três, 1984 (Biblioteca do Estudante da USP).

FIORIN, José Luiz. As astúcias da enunciação. São Paulo: Ática, 1996.

Semiótica das paixões: o ressentimento. Alfa, São Paulo, 51, v. 1, p. 9-22, 2007.

Elementos de análise do discurso. 14 ${ }^{\mathrm{a}}$ edição. São Paulo: Contexto, 2009. 
CASA, Vol.10 n.1, julho de 2012

FONTANILLE, J. Le tournant modal en sémiotique. Organon: Revista do Instituto de Letras da Universidade Federal do Rio Grande do Sul, v.23, p.175-190, 1995.

GREIMAS, Algirdas Julien. Da imperfeição. São Paulo: Hacker Editores, 2002.

GREIMAS, Algirdas Julien \& FONTANILLE, Jacques. Semiótica das paixões. Dos estados de coisas aos estados de alma. Trad. Maria José Rodrigues Coracini. São Paulo: Ática, 1993.

HOUAISS, Antônio e VILLAR, Mauro de Salles. Grande dicionário Houaiss de Língua Portuguesa. Rio de Janeiro: Objetiva, 2008.

LARA, Glaucia Muniz Proença e MATTE, Ana Cristina Fricke. Ensaios de semiótica: aprendendo com o texto. Rio de Janeiro: Nova Fronteira, 2009.

OLIVEIRA, Ana Cláudia. Estesia e experiência do sentido. CASA, v.8 n.2, p. 1-12, dez. 2010. 